\title{
Radiographic evaluation of bone maturations in children and adolescents living in Erzurum using Greulich-Pyle method
}

\author{
Cengiz Öztürk ${ }^{1}$ (D), Mete Özdikici ${ }^{2}$ (D), Samih Diyarbakır ${ }^{3}$ \\ ${ }^{1}$ Department of Anatomy, School of Medicine, Atatiirk University, Erzurum, Turkey \\ ${ }^{2}$ Department of Radiology, Istanbul Beylikdiizii Public Hospital, Istanbul, Turkey \\ ${ }^{3}$ Department of Anatomy, School of Medicine, Erzincan Binali Yildrrm University, Erzurum, Turkey
}

\begin{abstract}
Objectives: Bone age (BA) is used in age determination for a number of medico-legal reasons. One of the most commonly used radiographic methods in BA assessment is to compare hand-wrist radiographs with a standard reference. In this study, Greulich-Pyle (GP) method was used to determine the bone maturation values of a population of children and adolescents living in the city of Erzurum, Turkey.

Methods: Hand and wrist radiographs of 507 individuals (243 boys and 264 girls) aged between 7-19 years were evaluated and the BA was estimated by a radiologist using the GP method. Difference between estimated BA and chronological age (CA) was analyzed.

Results: In boys, except for the ages of 12,13 and 17 years, BA was significantly lower than the chronological age. In girls, BA was significantly lower than CA at 7, 8, 18 and 19 years of age, but not statistically different in the other ages.

Conclusion: According to the GP atlas, it is suggested that many factors including high altitude, cold climate, environment, nutrition, genetics, ethnics and socio-economic diversities might cause differences between BA and CA. Our results obtained in this study suggest that this method can guide the determination of bone age in children living in Erzurum, Turkey. However, in certain age groups for both genders, the GP method significantly underestimated skeletal age.
\end{abstract}

Keywords: adolescent; bone age; bone maturation; child; Erzurum

Anatomy 2019;13(1):21-26 @2019 Turkish Society of Anatomy and Clinical Anatomy (TSACA)

\section{Introduction}

Determination of the degree of skeletal maturation is generally defined as skeletal age or bone age $($ Bone Age $=\mathrm{BA})$ which is different from chronological age (CA) calculated by the date of birth of a healthy individual. ${ }^{[1]}$ In medicine, BA determination is used to provide the closest estimate of CA of a person. ${ }^{[2,3]}$ However, the processes of bone development might be adversely affected with various diseases, in addition to factors including race, genetic inclination, ethnicity, socio-economic status, geographical factors (altitude, climate) and gender. ${ }^{[4-12]}$

Although different methods are used in the determination of BA, the most commonly used ones are the Greulich-Pyle (GP), Tanner-Whitehouse (TW) 2 and
TW3 methods. Greulich and Pyle published the "Radiographic atlas of skeletal development of the hand and the wrist" in 1959 and the GP method was developed based on the bone maturation values of children and adolescents with high socio-economic status residing in the United States. The BA is determined by a comparison between the left hand-wrist radiograph of the subject to the nearest matching reference radiograph. The GP method is a relatively practical and frequently used method. ${ }^{[1]}$ On the other hand, TW2 method was developed in British children, in 1950s, based on European standards and descendants of Europeans. TW3 is a quantitative alternative of this method based on the skeletal maturity scores for each ossification center in the bones of hand and wrist. ${ }^{[13,14]}$ 
The GP atlas is applicable to most of the populations; however, some studies questioned the accuracy of the GP method, particularly in less developed countries including Turkey. Erzurum is a province located in the Eastern Anatolia with a cold climate and high altitude (approximately $2000 \mathrm{~m}$ ). It is a region where the production and consumption of animal foods is common and socio-economical level is moderate. This study was carried out to obtain information about the bone maturation in this region by referring to the GP atlas in children and adolescents.

\section{Materials and Methods}

This study approved by the review board of Ethics Committee. A total of 507 individuals, 243 males and 264 females aged between 7-19 years, born and raised in Erzurum region were included in the study. Individuals with a disease history that could adversely affect the bone development were excluded from the study population. The age of individuals was identified as day-month-year. The day values were then converted to the month value by \pm 15 days. A minimum of 15 girls and 15 boys were included in each age group. Evaluation of bone age by hand and wrist radiographs over 2 years of age is a wellaccepted method of evaluation. ${ }^{[4]}$

In this study, left hand and wrist postero-anterior radiographs of the children between the ages of 7-19 were used for investigation. Radiographs were obtained by focusing on the metacarpal per tube-film distance of $60 \mathrm{~cm} .{ }^{[1]}$ The bone age was determined by the same radi-

Table 1

Mean values of chronologic (CA) and bone ages (BA) in males.

\begin{tabular}{cccc}
\hline & \multicolumn{3}{c}{ BA (months) } \\
\cline { 2 - 4 } CA (months) & Min. & Max. & Mean \\
\hline 92.15 & 60 & 96 & 79.38 \\
98.86 & 72 & 108 & 88.00 \\
115.16 & 96 & 138 & 109.55 \\
125.52 & 108 & 132 & 122.28 \\
134.90 & 108 & 138 & 128.10 \\
151.65 & 132 & 162 & 151.20 \\
162.52 & 132 & 192 & 160.73 \\
173.90 & 162 & 186 & 172.00 \\
187.21 & 168 & 192 & 183.47 \\
195.35 & 180 & 204 & 192.00 \\
209.50 & 204 & 228 & 211.20 \\
218.33 & 204 & 216 & 214.66 \\
230.89 & 192 & 228 & 221.00 \\
\hline
\end{tabular}

ologist by comparing the closest standard bone age in the same gender group in the GP atlas. The subjects were divided into two main groups as boys and girls. Each group was divided into chronological age (CA) groups. $\mathrm{BA}$ averages and standard deviation (SD) values of each group were determined. The difference between CA and BA was calculated for each case. The arithmetic mean and standard deviation of this difference were determined for each age group. The collected data were subjected to statistical evaluation. The values of $\mathrm{BA}$ in each group and SD and CA were determined by using paired Student's t-test. The confidence interval for the BA and CA averages of the groups was determined with a level of $95 \%$. CA and BA correlations and significance were found in all age groups and genders. A statistical regression method was used for each of the female and male gender groups showing the least squares mean and linear correlation coefficients between BA and CA.

\section{Results}

This study was performed on a total of 507 individuals, consisting of 243 males and 264 females. The mean chronological ages (CA) of all groups in the 7-19 age range for males are shown as months in Table 1. In this table, average values of $\mathrm{BA}$ as well as the minimum and maximum values of $\mathrm{BA}$ are indicated in all age groups. The mean CA values for girls in each age group and mean, minimum and maximum $\mathrm{BA}$ values were calculated as months and shown in Table 2. CA values, mean BA values, difference of BA and $\mathrm{C}$ values and paired samples (p) values of each age group in males are shown in Table 3.

Table 2

Mean values of chronologic (CA) and bone ages (BA) in females.

\begin{tabular}{cccc}
\hline & \multicolumn{3}{c}{ BA (months) } \\
\cline { 2 - 4 } CA (months) & Min. & Max. & Mean \\
\hline 91.93 & 69 & 94 & 86.43 \\
101.60 & 82 & 106 & 97.60 \\
114.80 & 106 & 132 & 117.12 \\
125.00 & 106 & 144 & 131.10 \\
137.15 & 132 & 156 & 141.47 \\
150.95 & 132 & 156 & 150.54 \\
170.24 & 156 & 198 & 172.80 \\
171.68 & 156 & 180 & 171.27 \\
184.85 & 162 & 216 & 188.42 \\
196.61 & 180 & 204 & 198.28 \\
208.09 & 168 & 216 & 204.57 \\
219.66 & 180 & 216 & 208.00 \\
230.00 & 216 & 228 & 221.14 \\
\hline
\end{tabular}


Table 3

The differences between BA and CA in males.

\begin{tabular}{|c|c|c|c|c|c|c|c|c|c|c|c|}
\hline \multirow[b]{2}{*}{ Age (year) } & \multirow[b]{2}{*}{$\mathbf{n}$} & \multicolumn{2}{|c|}{ Chronologic age (CA) } & \multicolumn{2}{|c|}{ Bone age (BA) } & \multicolumn{2}{|c|}{ BA-CA differences } & \multicolumn{2}{|c|}{$\% 95$ confidence interval } & \multirow[b]{2}{*}{$\mathbf{t}$} & \multirow[b]{2}{*}{$\mathrm{p}$} \\
\hline & & Mean & SD & Mean & SD & Mean & SD & Min. & Max. & & \\
\hline 7 & 13 & 92.15 & 3.51 & 79.38 & 11.52 & -12.76 & 11.8 & 19.91 & 5.62 & 3.895 & 0.002 \\
\hline 8 & 15 & 98.86 & 2.89 & 88.00 & 12.55 & -10.86 & 10.8 & 16.85 & 4.87 & 3.891 & 0.002 \\
\hline 9 & 18 & 115.16 & 3.22 & 109.56 & 9.85 & -5.61 & 9.7 & 10.46 & 0.75 & 2.440 & 0.026 \\
\hline 10 & 21 & 125.52 & 3.32 & 122.29 & 8.99 & -3.23 & 8.1 & 6.96 & 0.48 & 1.814 & 0.085 \\
\hline 11 & 20 & 134.90 & 2.86 & 134.90 & 2.86 & 0.00 & 8.5 & 10.78 & 2.81 & 3.569 & 0.002 \\
\hline 12 & 20 & 151.65 & 2.32 & 151.20 & 9.04 & -0.45 & 7.9 & 4.16 & 3.28 & 0.252 & 0.804 \\
\hline 13 & 19 & 162.52 & 3.33 & 160.74 & 11.23 & -1.78 & 10.1 & 6.67 & 3.09 & 0.770 & 0.452 \\
\hline 14 & 21 & 173.90 & 3.52 & 172.00 & 6.92 & -1.90 & 7.4 & 5.27 & 1.46 & 1.179 & 0.252 \\
\hline 15 & 19 & 187.21 & 2.82 & 183.47 & 7.56 & -3.73 & 6.9 & 7.07 & 0.39 & 2.349 & 0.030 \\
\hline 16 & 20 & 195.35 & 3.81 & 192.00 & 7.53 & -3.35 & 6.4 & 6.34 & 0.35 & 2.337 & 0.031 \\
\hline 17 & 20 & 209.50 & 4.11 & 211.20 & 8.16 & +1.70 & 5.7 & 0.99 & 4.39 & 1.322 & 0.202 \\
\hline 18 & 18 & 218.33 & 2.86 & 214.67 & 3.88 & -3.66 & 4.7 & 6.01 & 1.31 & 3.290 & 0.004 \\
\hline 19 & 19 & 230.89 & 2.88 & 221.06 & 10.05 & -9.84 & 9.1 & 14.26 & 5.41 & 4.674 & 0.001 \\
\hline
\end{tabular}

The difference between BA and CA values for males were significant at the ages of 7 years $(p<0.01), 8$ years $(\mathrm{p}<0.01), 9$ years $(\mathrm{p}<0.05), 11$ years $(\mathrm{p}<0.01), 15$ years $(\mathrm{p}<0.05), 16$ years $(\mathrm{p}<0.05), 18$ years $(\mathrm{p}<0.01)$ and 19 years $(\mathrm{p}<0.001)$. On the other hand, no significant difference was observed at the $10,12,13,14$ and 17 age groups. These data indicated that the mean BA of males between $7-19$ years was 4.27 months lower than the chronological age in Erzurum. The standard deviation values of the difference of BA and CA were between 4.7 and 11.8 for males, whereas they were between 5.42 and 13.28 in females, indicating some individual variations in the values.

Following a similar approach, mean CA, BA, difference between BA and CA values and p-value for females are shown in Table 4. The difference between BA and

Table 4

The differences between BA and CA in females.

\begin{tabular}{|c|c|c|c|c|c|c|c|c|c|c|c|}
\hline \multirow[b]{2}{*}{ Age (year) } & \multirow[b]{2}{*}{$\mathbf{n}$} & \multicolumn{2}{|c|}{ Chronologic age (CA) } & \multicolumn{2}{|c|}{ Bone age (BA) } & \multicolumn{2}{|c|}{ BA-CA differences } & \multicolumn{2}{|c|}{$\% 95$ confidence interval } & \multirow[b]{2}{*}{$\mathrm{t}$} & \multirow[b]{2}{*}{$\mathbf{p}$} \\
\hline & & Mean & SD & Mean & SD & Mean & SD & Min. & Max. & & \\
\hline 7 & 16 & 91.93 & 2.90 & 86.43 & 7.58 & -5.50 & 6.01 & 8.70 & 2.29 & 3.660 & 0.002 \\
\hline 8 & 15 & 101.60 & 3.10 & 97.60 & 9.47 & -4.00 & 7.16 & 7.96 & 3.41 & 2.163 & 0.048 \\
\hline 9 & 16 & 114.81 & 2.80 & 117.12 & 9.74 & +2.31 & 9.00 & 2.48 & 7.11 & 1.027 & 0.321 \\
\hline 10 & 20 & 125.00 & 3.19 & 131.10 & 11.77 & +6.10 & 9.90 & 1.46 & 10.73 & 2.753 & 0.013 \\
\hline 11 & 19 & 137.15 & 3.45 & 141.47 & 7.56 & +4.31 & 8.26 & 0.33 & 8.30 & 2.276 & 0.035 \\
\hline 12 & 22 & 150.95 & 3.48 & 150.54 & 6.90 & -0.41 & 5.68 & 2.93 & 2.11 & 0.337 & 0.739 \\
\hline 13 & 25 & 170.24 & 9.18 & 172.80 & 10.39 & +2.56 & 9.84 & 1.50 & 6.62 & 1.301 & 0.206 \\
\hline 14 & 22 & 171.68 & 3.28 & 171.27 & 8.22 & -0.40 & 7.76 & 3.85 & 3.03 & 0.247 & 0.807 \\
\hline 15 & 28 & 184.85 & 3.43 & 188.42 & 13.35 & +3.57 & 13.28 & 1.57 & 8.72 & 1.423 & 0.166 \\
\hline 16 & 21 & 196.61 & 4.16 & 198.28 & 7.21 & +1.66 & 7.24 & 1.62 & 4.96 & 1.055 & 0.304 \\
\hline 17 & 21 & 208.09 & 3.74 & 204.57 & 11.04 & -3.52 & 10.47 & 8.29 & 1.24 & 1.541 & 0.139 \\
\hline 18 & 18 & 219.66 & 3.89 & 208.00 & 9.20 & -11.66 & 9.10 & 16.19 & 7.13 & 5.435 & 0.001 \\
\hline 19 & 21 & 230.00 & 2.60 & 221.14 & 6.08 & -8.85 & 5.42 & 11.32 & 6.38 & 7.482 & 0.001 \\
\hline
\end{tabular}


CA values for females were significant at the ages of 7 $(p<0.01), 8 \quad(p<0.05), 10 \quad(p<0.05), 11 \quad(p<0.05), 18$ $(\mathrm{p}<0.001)$, and $19(\mathrm{p}<0.001)$. However, in age groups of $9,12,13,14,15,16$ and 17 years, differences were not significantly different. In this table, mean BA was 1.06 months underestimated than the average CA in the categories of 7-19 years of age.

A series of statistical procedures and regression analyses were performed for a global relationship between BA and CA. For males, the test statistics were calculated by using the formula of $y=a+b x$ in which $x=C A, y=B A$, and $\mathrm{t}=38.586, \mathrm{p}<0.001, \mathrm{y}=-9.924+1.035 \mathrm{x}$. For females, $\mathrm{b}>0$, $\mathrm{t}$ : 29.158, $\mathrm{p}<0.001$ were formulated as $\mathrm{y}=6.062+0.956 \mathrm{x}$. The linear correlation coefficient $\mathrm{r}$ was 0.996 for males and 0.994 for females, displaying a strong correlation in both genders.

\section{Discussion}

In this study, we aimed to investigate the accuracy and reliability of the GP method in a local population of children and adolescents living in the city of Erzurum, Turkey. The difference of the mean BA and CA was generally negative in all age groups. Especially at 7, 8 and 19 year age groups, differences were more significant. Among the investigated age groups, the difference between the average $\mathrm{BA}$ and $\mathrm{CA}$ values were positive only in the 17-year-olds. However, this difference was not statistically significant. In this study, mean bone ages of 7-19 year-old males estimated by the GP-method were 4.27 months behind the $\mathrm{CA}$ values.

The differences between BA-CA values in males were negative between the ages of $7-11$. This negativity was more prominent between ages 18-19, but less between ages 11-17. Although, the mean differences of BA and CA values in females between the ages 9-16 showed relatively positive values in general, it was negative in the age groups of 7-8 and 18-19. Despite the fact that the age of puberty in Turkey is generally accepted as in the range of 12-20 years in males and 10-18 in females, bone maturation develops earlier with the values of 11-17 years in males and 9-16 years in females, reflecting the effect of pubertal period $^{[15]}$ In studies conducted in other countries, BA in males and females usually showed negative values in the preadolescent period. ${ }^{[8,16-18]}$ However, in adolescents, BA was found to be equal to $\mathrm{CA}$ in males and females, or even higher than those of CA values. ${ }^{[8,18-21]}$

Previous studies suggested that bone maturation is enhanced in both females and males in specific age groups. Especially during the puberty, the effects of sex hormones accelerate bone maturation in females and males, although female sex hormones might be more effective than the male hormones. ${ }^{[2]}$

Our results also showed a regression in BA during the pre-adolescent period in both males and females. There was a significant negativity in boys at the age of 7 and 8 . Similarly, a significant negativity was also observed in girls at 7 and 8 years old. In Erzurum, the mean BA of 7 to 19 year-old females was 1.06 months behind the CA. This indicates that BA value is close to CA value in girls. On the other hand, the highest standard deviation of the BA was roughly one year in both males and females. While documenting the age identity of individuals, declaration of persons was taken into consideration, but minor error margins should be taken into consideration, due to possible delays in the official recordings of date of birth certificates. In spite of the absence of reliable information, this study suggests that GP method provides valuable data in predicting the CA values and gives a basic information.

In another study conducted in Turkish children, SD values were found over a year. ${ }^{[23]}$ In general, BA is used for age determination in forensic medicine. Especially for medico-legal and forensic interests, it is important to draw erroneous conclusions of adulthood based on the finding of full skeletal maturity by radiographic methods. It is stated that the age of consent in law starts with the substitution of 18 years of age ${ }^{[2]}$ Therefore, errors in the estimation of age could result in children being considered by the legal system as adults and vice versa. This study displayed several instances of children under 18 years of age having attained full skeletal maturity, as well as individuals 18 years and older with immature skeletons.

Although, our study population is different from the reference population originally studied by Greulich and Pyle in several ways, our findings suggest that reliance on the GP method as evidence for age determination in defendants of uncertain age lacks a basis in the scientific literature.

In boys, the difference between $\mathrm{BA}$ and $\mathrm{CA}$ at the onset of age of consent (18 years) and at the age of 19 years were $-3.66 \pm 4.7$ and $-9.84 \pm 9.1$ months, respectively. However, in girls, there was a very significant difference between BA and CA in both at the age of consent $(-11.66 \pm 9.10$ months) and also at the age of 19 years $(-8.85 \pm 5.42$ months). Individual differences are found in these values presented in Tables 3 and 4, due to factors affecting bone maturation in determining age determination, in our study population in Erzurum, the bone maturation level of boys at the age of 18 displayed a delay of approximately 8 months in comparison to girls. However, this difference between 
males and females decreased at other ages. In the literature, differences in bone maturation between boys and girls were also reported similar to our study. ${ }^{[6,7]}$

In this study, males showed a delayed maturation of 3.21 months compared to females with an average of 7-19 ages. In Ireland, bone maturation age of males was reported as 2.3 years behind of females; but this difference was lower in countries such as Denmark, Greenland and Australia. ${ }^{[3,6,724]}$ In a longitudinal study, the genetic slope was lower at the first 3 months of life, associated with the breast-feeding period. The growth rate was depressed in countries with low-middle socio-economic backgrounds, in comparison to North American and European standards. ${ }^{[5]}$ This study indicates that socio-economic factors are more effective at the $7-19$ years of age.

The effects of living in high altitude also has a special importance on child growth and development. In general, people born and raised at a high altitude tend to have lower birth weight, slower growth rate, longer period of growth, poorly defined adolescent growth spurt and delay in psychomotor development, compared to children living at the sea level. ${ }^{[1]]}$ In Erzurum, the high altitude up to 2000 meters might cause a delay in bone maturation by affecting the genetic slope. Bone maturation was 4.27 months behind the CA of males and 1.06 months behind for females in this study. Even more negativity was detected in the sampled population, as related to the socio-economic level. On the other hand, consumption of adequate dairy products might have a positive effect on bone mineralization and might have decreased the extent of delay in bone maturation. ${ }^{[25]}$ As a matter of fact, in a number of studies, it has been emphasized that nutrition and socio-economic factors affect bone maturation significantly. ${ }^{[5,9,16,26-28]}$ In another study conducted in Turkey around Sivas province, which also has a high altitude and cold climate, partial retardation was detected in comparison to Malatya which has a lower altitude. ${ }^{[29]}$ Therefore, climate, nutrition and socio-economic factors are thought to play an important role on the growth rate of children. It is also pointed out that warm climate and hot environment cause premature maturation. ${ }^{[12]}$ In China, Harbin, BA values of urban children were found ahead of the CA and ahead of the United Kingdom's standard. ${ }^{[8]}$ Also, in Sweden with a cold climate, the BA was higher and further developed than those of in the United Kingdom. ${ }^{[30]}$ In spite of the cold climate, genetic influences and socio-economic factors might exert stronger effect on the growth rates rather than the effects of climate and nutrition. The individuals living in Erzurum have a genetic inclination for about 1000 years of people living in the geography of this region and also a genetic affinity of the middle Asia inhabited by long years.

BA under the age of 3-year displays more genetic tendency; however, BA of the individuals are affected more from the influences of the socio-economical factors after the age of 3 . Since this study covers the children and adolescents at the 7-19 age group, the effects of genetic tendency was less influential than the socio-economic factors.

\section{Conclusion}

In this study, the mean BA of children between the ages 7-19 in Erzurum was calculated using the GP method and found approximately 4.27 and 1.06 months behind the mean CA of males and females, respectively. Due to the fixed ethnic and socio-economic groups of children selected for the generation of GP atlas, its applicability varies in different parts of the world. The differences between BA and CA are thought to be caused by many factors such as high altitude, cold climate, environment, nutrition, genetic, ethnic and socio-economic factors. The findings of our study suggest that the GP method method is useful in determining the bone maturation of children and adolescents living in Erzurum, Turkey. However, in certain age groups for both genders, the GP method might significantly underestimate the skeletal age.

\section{Acknowledgement}

This manuscript was prepared from the $\mathrm{PhD}$ thesis of Cengiz Öztürk.

\section{References}

1. Greulich WW, Pyle SI. Radiographic atlas of skeletal development of the hand and wrist. 2nd ed. Stanford (CA): Stanford University Press; 1959. p. 50-250.

2. The Turkish Civil Code Law No. 4721. Official Gazette, Date: 8.12.2001, Article 11.

3. Gardner E, Gray DJ, O'Rahilly R. Anatomy. Philadelphia (PA): WB Saunders; 1969. pp. 279-83.

4. Levine $\mathrm{E}$. The contributions of the carpal bones and the epiphyseal centres of the hand to the assessment of skeletal maturity. Hum Biol 1972;44:317-27.

5. Marshall WA, Ashcroft MT, Bryan G. Skeletal maturation of the hand and wrist in Jamaican children. Hum Biol 1970;42:419-35.

6. Jiménez-Castellanos J, Carmona A, Catalina-Herrera CJ, Viñuales M. Skeletal maturation of wrist and hand ossification centers in normal Spanish boys and girls: a study using the Greulich-Pyle method. Acta Anat 1996;155:206-11.

7. Lejarraga H, Guimarey L, Orazi V. Skeletal maturity of the hand and wrist of healthy Argentinian children aged 4-12 years, assessed by the TWII method. Ann Hum Biol 1997;24:257-61.

8. Zhen OY, Baolin L. Skeletal maturity of the hand and wrist in Chinese school children in Harbin assessed by the TW2 method. Ann Hum Biol 1986;13:183-7. 
9. Melsen B, Wenzel A, Miletic T, Andreasen J. Dental and skeletal maturity in adoptive children: assessments at arrival and after one year in the admitting country. Journal Ann Hum Biol 1986;13:153- 9.

10. Ashizawa K, Asami T, Anzo M, Matsuo N, Matsuoka H, Murata M, Ohtsuki F, Satoh M, Tanaka T, Tatara H, Tsukagoshi K. Standard RUS skeletal maturation of Tokyo children. Ann Hum Biol 1996;23: 457-69.

11. Pawson IG. The effects of high altitudes on child growth and development. Int J Biometeorol 1977;21:171-8.

12. Wells JC. Environmental temperature and human growth in early life. J Theor Biol 2000;204:299-305.

13. Tanner JM, Whitehouse RH, Cameron N, Marshall WA. Assessment of skeletal maturity and prediction of adult height (TW2 method). London: Academic Press; 1975. p. 99.

14. Ahmed ML, Warner JT. TW2 and TW3 bone ages: time to change? Arch Dis Child 2007;92:371-2.

15. Neyzi O. Ertuğrul C. Koç L. Child health and diseases. [Book in Turkish] Istanbul: Istanbul Faculty of Medicine Foundation \& Bayda Publications; 1984. p. 21-4.

16. Takai S, Akiyoshi T. Skeletal maturity of Japanese children in Western Kyushu. Am J Phys Anthropol 1983;62:199-204.

17. Takai S. Smoothed skeletal maturity curve of Japanese children by Tanner-Whitehouse 2 (TW2) method and its application. Kaibogaku Zasshi 1990;65:436-47.

18. Kimura K. Skeletal maturity of the hand and wrist in Japanese children in Sapporo by the TW2 method. Ann Hum Biol 1977:44953.

19. Helm S. Skeletal maturity in Danish school children assessed by the TW2 method. Am J Phys Anthrop 1979;51:345-52.

20. Kimura K. Skeletal maturity of the hand and wrist in Japanese children by the TW2 method. Ann Hum Biol 1977;4:353-6.

ORCID ID:

C. Öztürk 0000-0002-2000-4952; M. Özdikici 0000-0001-6309-8306; S. Diyarbakır 0000-0001-6755-7741
21. Waldmann E, Baber FM, Field CE, Billewicz WZ, Thomson AM. Skeletal maturation of Hong Kong Chinese children in the first five years of life. Ann Hum Biol 1977;4:343-52.

22. Bloom W. A textbook of histology. Philadelphia (PA): WB Saunders; 1968. p. 144-69

23. Büken B, Safak AA, Yazici B, Büken E, Mayda AS. Is the assessment of bone age by the Greulich-Pyle method reliable at forensic age estimation for Turkish children? Forensic Sci Int 2007;173:146-53.

24. Magnússon TE. Skeletal maturation of the hand in Iceland. Acta Odontol Scand 1979;37:21-8.

25. Katzman DK, Bachrach LK, Carter DR, Marcus R. Clinical and anthropometric correlates of bone mineral acquisition in healthy adolescent girls. J Clin Endocrinol Metab 1991;73:1332-9.

26. Murata M. Characteristics of pubertal growth in Japanese children from the standpoint of skeletal growth. Acta Paediatr Jpn 1992;34:236-42.

27. Liu B, Wang D, Wang Z. Comparison of skeletal development between rural and urban school-age children. [Article in Chinese] Zhongguo Yi Xue Ke Xue Yuan Xue Bao 1994;16:165-9.

28. Jahari AB, Saco-Pollitt C, Husaini MA, Pollitt E. Effects of an energy and micronutrient supplement on motor development and motor activity in undernourished children in Indonesia. Eur J Clin Nutr 2000;54:60-8.

29. Öztürk F, Karataş OH, Mutaf HI, Babacan H. Bone age assessment: comparison of children from two different regions with the Greulich-Pyle method in Turkey. Australian Journal of Forensic Sciences 2016;48:1-10.

30. Taranger J, Karlberg J, Bruning B, Engström I. Standard deviation score charts of skeletal maturity and its velocity in Swedish children assessed by the Tanner-Whitehouse method (TW2-20). Ann Hum Biol 1987;14:357-65.

Correspondence to: Cengiz Öztürk, PhD

Department of Anatomy, School of Medicine, Atatürk University,

Erzurum, Turkey

Phone: +90 5334258522

e-mail: cozturk25@gmail.com

Conflict of interest statement: No conflicts declared.

This is an open access article distributed under the terms of the Creative Commons Attribution-NonCommercial-NoDerivs 3.0 Unported (CC BY-NCND3.0) Licence (http://creativecommons.org/licenses/by-nc-nd/3.0/) which permits unrestricted noncommercial use, distribution, and reproduction in any medium, provided the original work is properly cited. Please cite this article as: Öztürk C, Özdikici M, Diyarbakır S. Radiographic evaluation of bone maturations in children and adolescents living in Erzurum using Greulich-Pyle method. Anatomy 2019;13(1):21-26. 